\title{
CAMBIOS CELULARES POR ANTICONCEPTIVOS ORALES
}

Milena Alfonso, Johanna Chamorro, Kelly Rada, Giovanni Tique.*

\section{Resumen}

Los anticonceptivos orales son medicamentos de amplio uso en las mujeres en edad fértil. Pueden causar alteraciones citológicas que confunden al observador, tanto en el exo y endocérvix como en el endometrio. Se describen e ilustran estos cambios que en ocasiones simulan carcinomas, pero que nunca lo producen.

\section{Introducción}

Los anticonceptivos orales se introdujeron al mercado en 1960 como método de planificación hormonal. Desde entonces se ha tratado de disminuir la concentración de estrógenos y progestágenos, para reducir los efectos secundarios que pueden causar en la mujer, pero manteniendo su eficacia anticonceptiva. ${ }^{1}$

El endoexocérvix no sólo reacciona ante las hormonas endógenas sino que también puede cambiar al administrar exógenas. Estas modificaciones dependen del tipo de preparado del anticonceptivo, la dosis y el tiempo de planificación. La administración de hormonas puede alterar la lectura de las láminas tanto citológicas como histológicas, causando falsos positivos si no se tiene conocimiento sobre las modificaciones que pueden ocurrir.

\section{Exocérvilx}

Las hormonas sexuales actúan sobre el exocérvix de la mujer sexualmente madura, causando cambios cíclicos como resultado de la producción periódica de estrógenos y progestágenos en los ovarios. El epitelio escamoso también responde a la administración de hormonas exógenas de acuerdo con la dosis. ${ }^{2}$ Uno de los cambios más comunes es el índice cariopicnótico. En los tratamientos en que predominan los estrógenos, permanece alto entre 30 y $90 \%$, en contraste con las terapias basadas en la progesterona en donde dicho índice baja del $10 \%$ hasta $0 \%{ }^{3}$

\footnotetext{
* Estudiantes Facultad de Citohistotecnología VI semestre

** Este trabajo fue realizado bajo la tutoría de la Sra. Yaneth León Encizo, Instructora Asociada y Citohistotecnóloga, Fundación Universitaria de Ciencias de la Salud, y de la Sra. Martha Cecilia Diaz, Citohistotecnóloga del Instituto Nacional de Cancerología.
}

La seudoparaquetatosis se refiere a las alteraciones citológicas semejantes a la paraqueratosis, como las observadas en células escamosas degeneradas en los frotis atróficos de las mujeres posmenopáusicas. También se ve cuando el tratamiento con anticonceptivos orales contiene cantidad importante de progesterona ${ }^{4}$ (Figura 1).

\section{Endocérvix}

Los cambios celulares que causan los anticonceptivos orales en el endocérvix son muy similares a los producidos por el dispositivo intrauterino (DIU). La acción de la progesterona induce al aumento de la producción de moco en las células endocervicales, lo cual lleva a la formación de vacuolas en el citoplasma. No es frecuente encontrar células con rasgos aparentes de anormalidad. Lo que suele observarse es la presencia de células con aumento del tamaño nuclear, bio multinucleaciones, cromatina gruesa y escaso o nulo citoplastama, cambios que desaparecen al interrumpir el tratamiento hormonal $^{3}$ (Figuras 2 y 3).

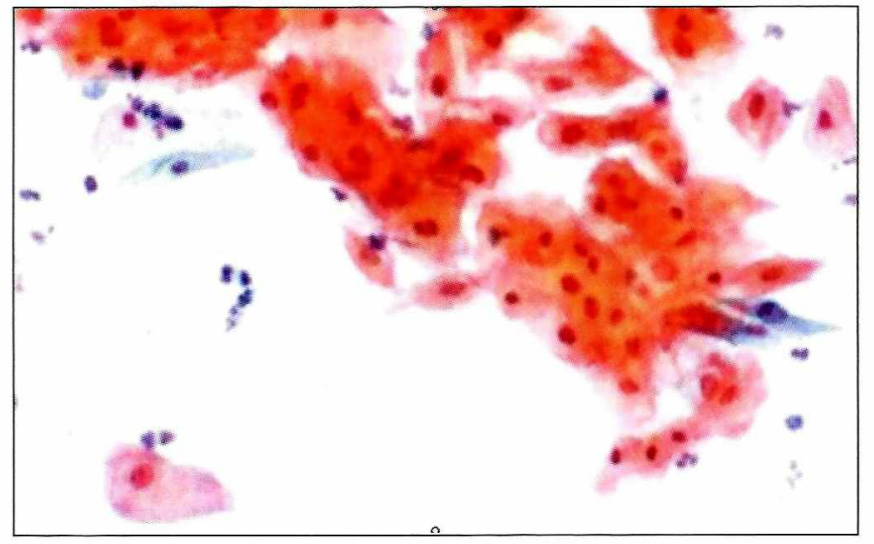

Figura I. Pseudoparaqueratosis inducida por progesterona. 


\section{Endometrio}

Los cambios que inducen los anticonceptivos orales sobre el endometrio dependen de varios factores como:

- Tipo o mezcla de hormonas utilizadas.

- Dosis y tiempo durante el cual se han administrado.

- Modo de administración.

- Edad de la paciente.

- Receptibilidad del endometrio.

\section{Reacción decidual}

Es el cambio que sufren las células estromales del endometrio, caracterizado por agrandamiento celular y citoplasma claro, rico en glucógeno. ${ }^{5}$ Las células estromales localizadas fuera del endometrio pueden presentar decidualización debido a la estimulación hormonal. En el

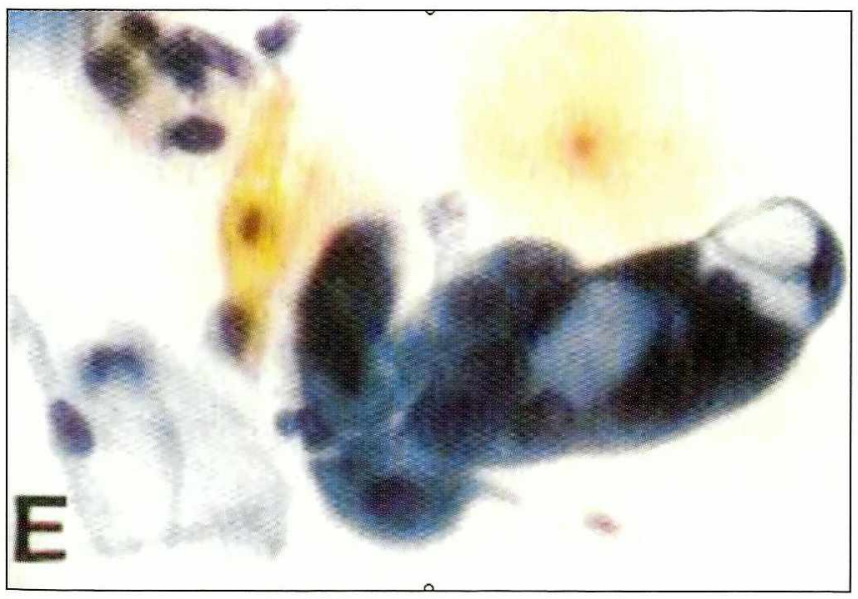

Figura 2. Cambios en el endocérvix con aumento del tamaño nuclear y vaculas citoplasmicas.

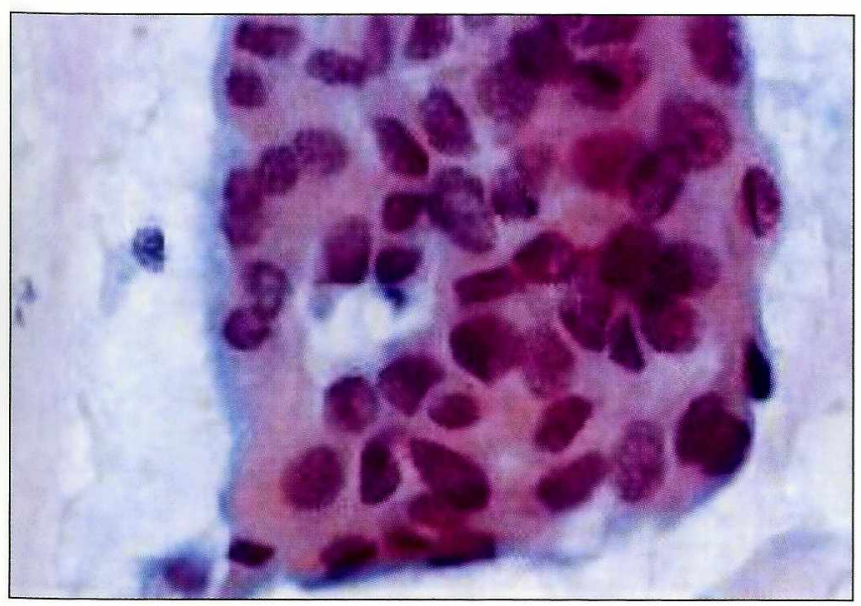

Figura 4. Cambio decidual en las células estromales por acción progestacional. estroma del cuello uterino también puede ocurrir, pero es necesario que haya una erosión del epitelio de superficie o de un pólipo de tejido decidual para que las células deciduales aparezcan en la citología (Figura 4).

\section{Endometrio proliferativo}

En los casos en los que hay una alta influencia estrogénica el endometrio se va a tornar proliferativo. Si esta alta influencia persiste, se pueden observar imágenes de hipertrofia nuclear, superposición y presencia de nucleolos, que hacen pensar en cuadros hiperplásicos (Figura 5).

\section{Endometrio secretor}

Es frecuente observar este cuadro en la ingesta de anticonceptivos orales combinados con dosis bajas, de escasa potencia y de tipo combinado. Las glándulas del

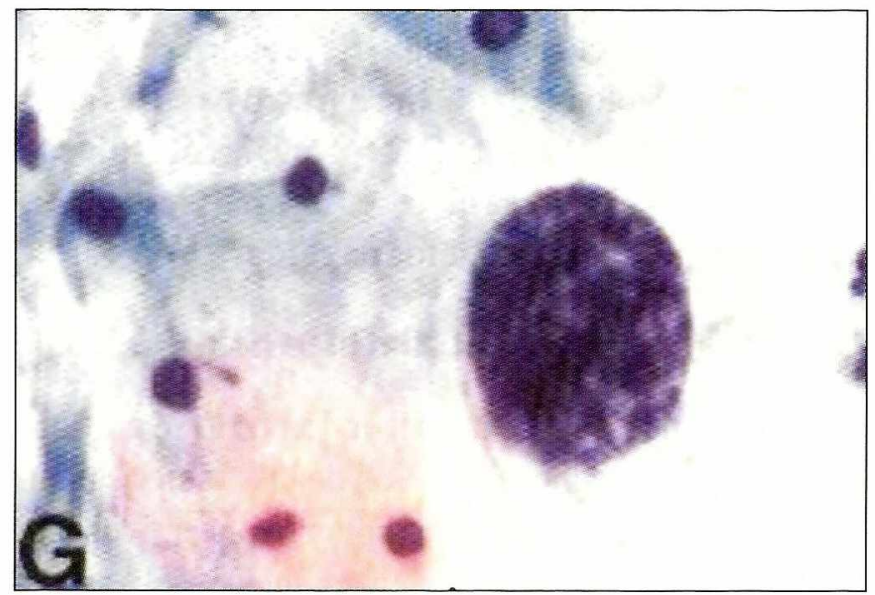

Figura 3. Acción de la progesterona en células endocervicales.

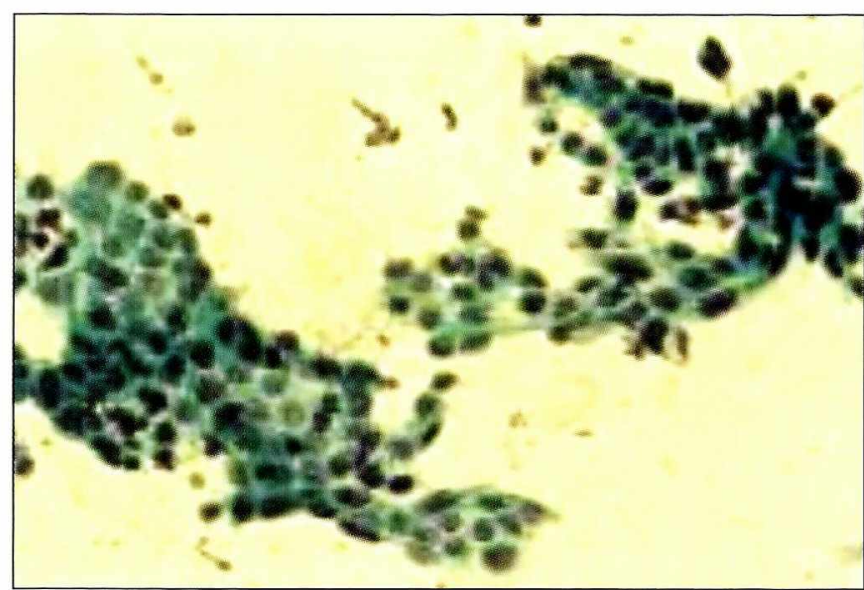

Figura 5. Hipertrofia nuclear, superposicion y nucléolos evidentes en células endometriales con acción estrogénica por anticonceptivos. 
endometrio secretor son estrechas o levemente tortuosas revestidas por células inactivas con citoplasma vacuolado y borde apical regular, que a veces contienen secreción densa eosinófila, acompañada de abundante estroma interpuesto, con intenso edema al inicio del tratamiento.

\section{Endometrio atrófico}

Aparece luego de terapias prolongadas con anticonceptivos orales. El endometrio presenta glándulas atróficas, estrechas, que muestran algunos cambios secretores. Las células estromales son grandes, pero sin cambios deciduales manifiestos. La relación estroma/glándulas esta incrementada a favor del primero y si este cuadro persiste, se puede llegar a la atrofia total del endometrio sin recuperación de la función postratamiento. ${ }^{5}$

\section{Endometrio disociado}

Se caracteriza por la presencia de glándulas atróficas y reaccion predecidual extensa. Se produce ante la administración prolongada de anticonceptivos orales combinados, se observan glándulas pequeñas, rectilíneas, tapizadas por epitelio inactivo y el estroma presenta una marcada reacción decidualiforme (Figura 6).

\section{Inflamación crónica del endometrio}

La inflamación crónica del endometrio se produce como respuesta a una alteración de las defensas naturales que pueden ser causadas por anticonceptivos orales. Este cuadro es poco frecuente y suele resolverse en el curso de las menstruaciones (Figura 7).

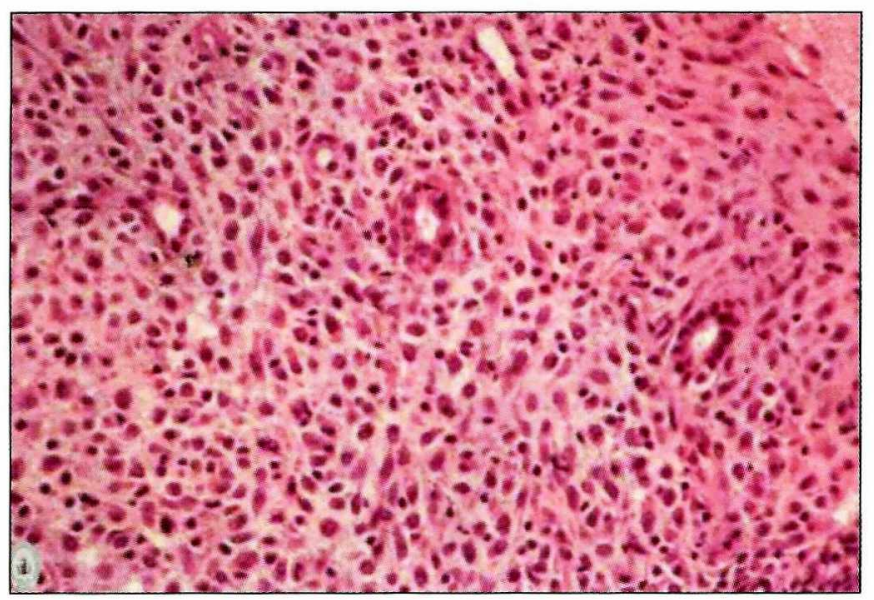

Figura 6. Glandulas atroficas y reaccion predecidual en el endometrio.
Citológicamente la inflamación crónica se caracteriza por una presencia masiva de elementos celulares como plasmocitos, linfocitos e histiocitos que se acumulan en la cavidad uterina. ${ }^{5}$

\section{Hiperplasia microglandular}

La hiperplasia microglandular cervical es una lesión benigna pseudotumoral, secundaria al efecto de la progesterona como sucede durante la administración de anticonceptivos orales y con el embarazo.

Se observan extensas láminas de células con distribución regular, núcleos con ligero agrandamiento e hipercromáticos. El citoplasma es cilíndrico o poligonal y puede ser amplio con vacuolas. En el fondo suelen verse abundantes células inflamatorias (Figura 8).

Cuando hay hiperplasia microglandular atípica, el diagnóstico diferencial es con el adenocarcinoma endocervical in situ o invasor y el adenocarcinoma endometrial (Figura 9). . $^{3-4}$

\section{Células de Arias-Stella}

Las células de Arias-Stella no son frecuentes en extendidos citológicos. Se observan en las células del endometrio, pero pueden también localizarse en endocérvix y trompa de Falopio. Suelen presentarse en pacientes gestantes y rara vez después de anovulatorios orales o drogas inductoras de la ovulación.

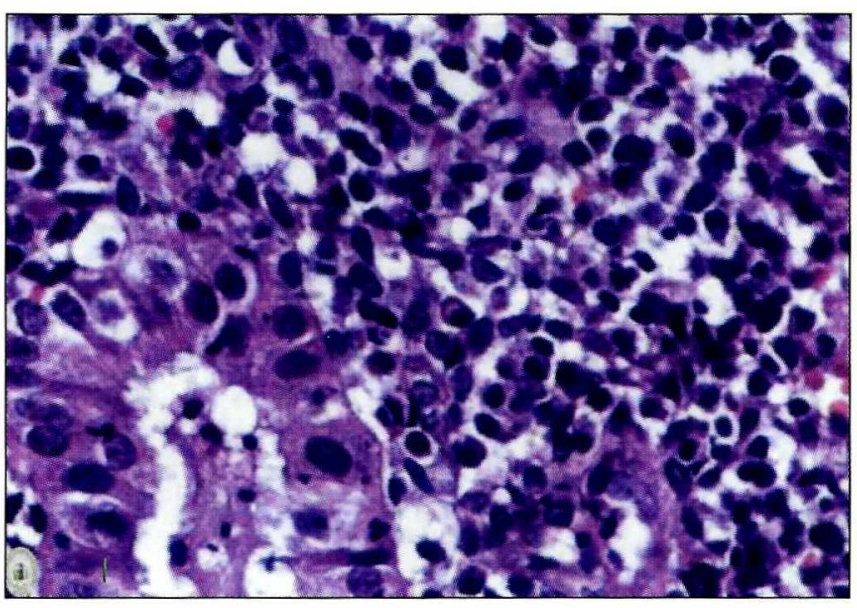

Figura 7. Células endometriales con infiltrado inflamatorio por linfocitos, histiocitos y plasmocitos. 
La morfología de las células de Arias-Stella se caracteriza por tener abundante citoplasma con microvacuoliza-

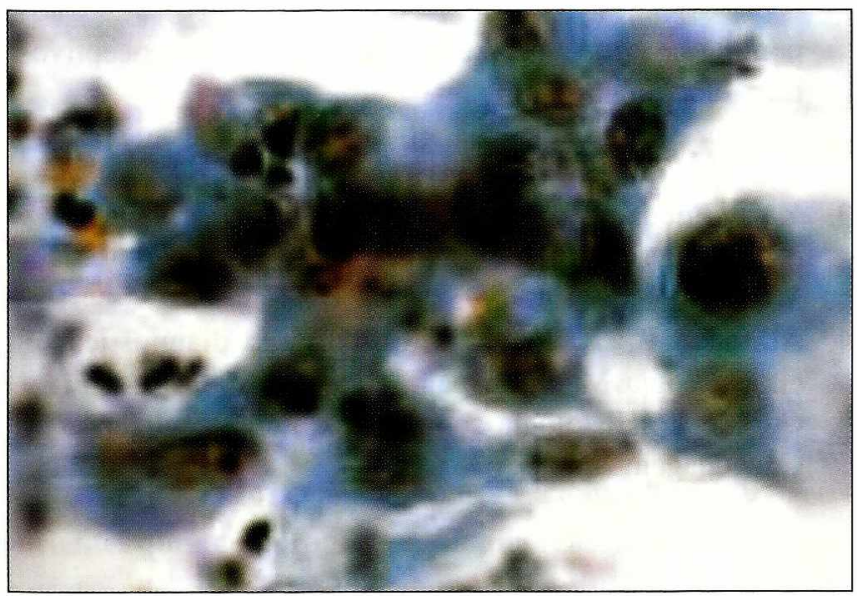

Figura 8. Nucléolos grandes e hipercromáticos en hiperplasia microglandular endocervical.

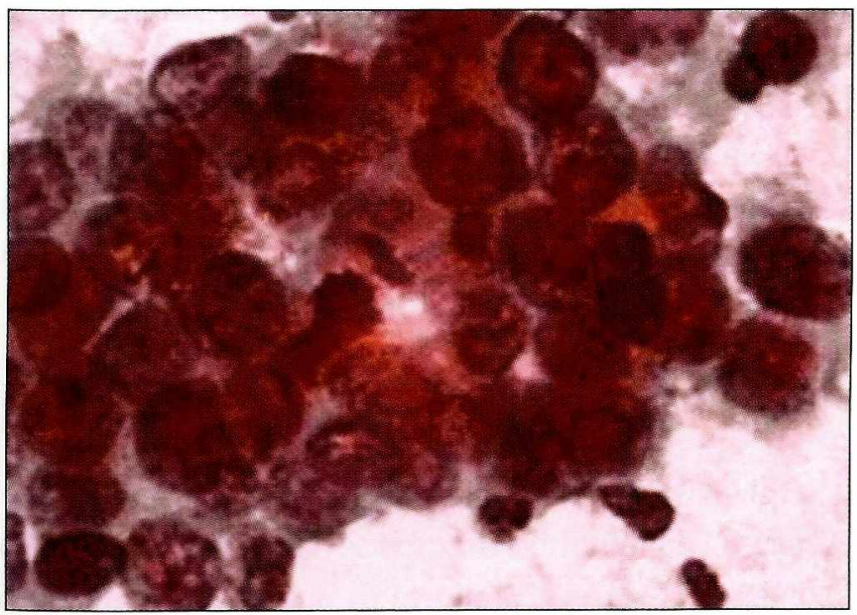

Figura 9. Hiperplasia microglandular atípica del endocérvix por acción de anticonceptivos.

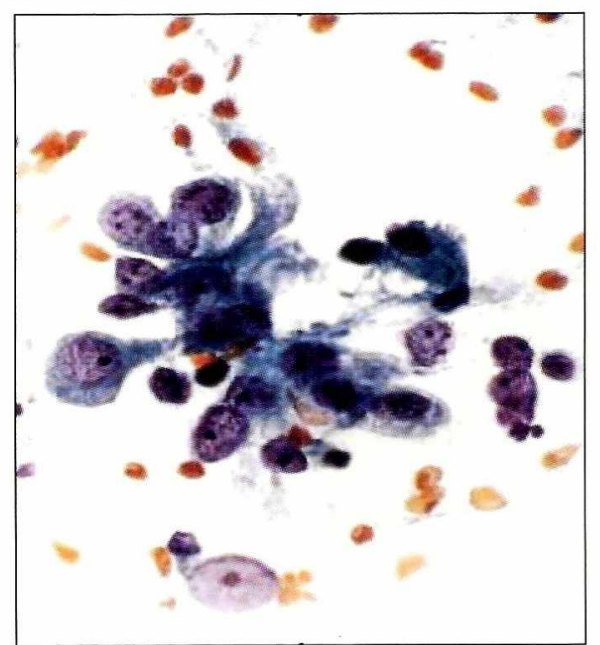

Figura II. Células endometriales con aumento del tamaño nuclear, pleomorfismo e hipercromasia. ciones, son $\mathrm{PAS}+\mathrm{y}$ presentan marcada atipia nuclear como lo es el aumento del tamaño, pleomorfismo e hipercromasia (Figura 10). El diagnóstico diferencial es con el adenocarcinoma de células claras (Figura 11). ${ }^{3}$

\section{Leiomioma}

Es el tumor uterino más frecuente que no tiene potencial maligno. Ocurre en una de cuatro mujeres en edad fértil. Aumenta de tamaño cuando se realizan terapias con anticonceptivos orales con estrógenos o en el embarazo (Figura 10). Histológicamente están constituidos por haces de musculatura lisa, desordenados y más celulares que el miometrio normal (Figura 12). ${ }^{7}$

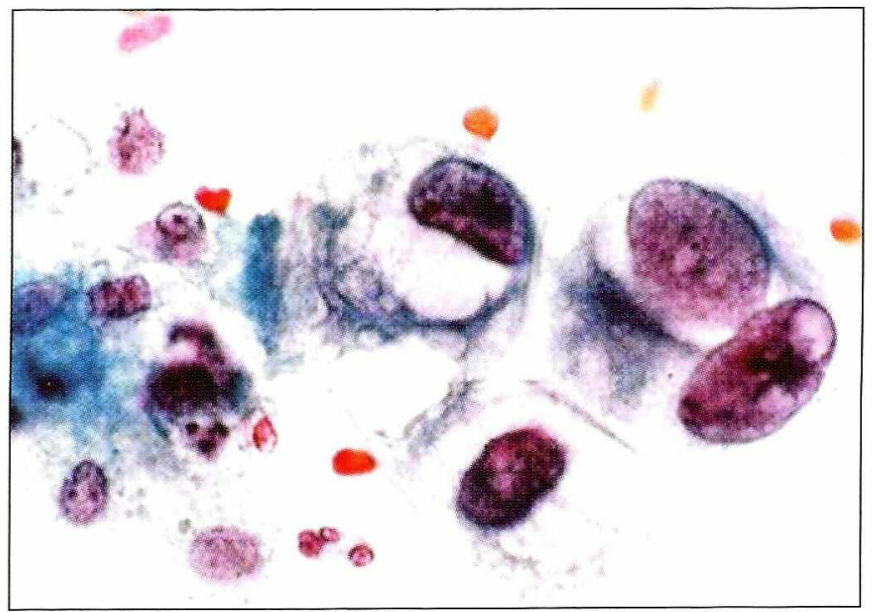

Figura 10. Cambio de Arias-Stella en células endometriales con atipia nuclear y citoplasma con microvacuolas.

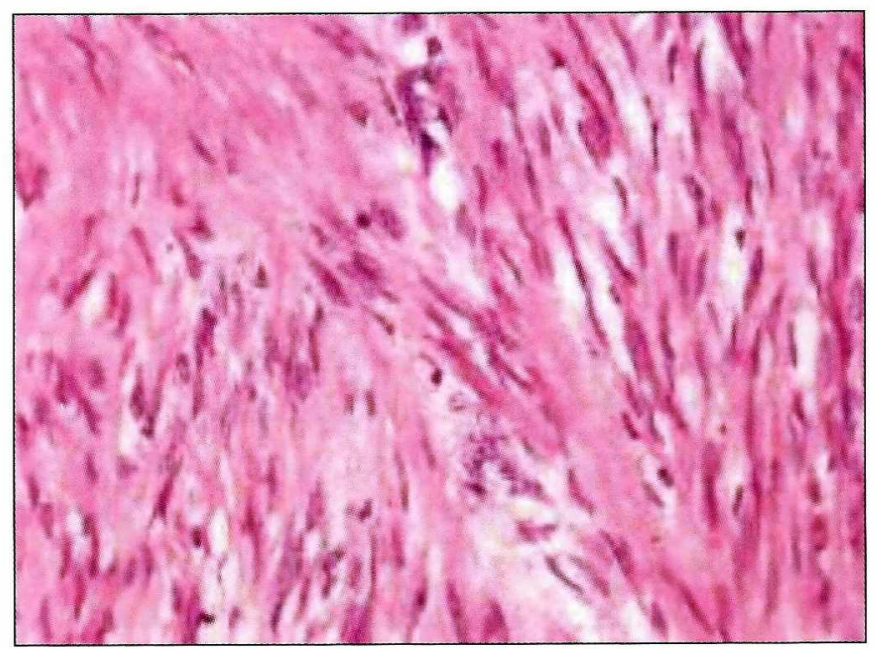

Figura I2. Haces de músculo liso en un leiomioma. 


\section{Conclusión}

Con esta revisión podemos concluir que los anticonceptivos orales producen cambios no tumorales en el epitelio y estroma del endoexocérvix, que se pueden confundir con lesiones tumorales causando falsos positivos. Por tal motivo, es importante conocer estas alteraciones y sus diagnósticos diferenciales para la conclusión acertada.

\section{Referencias}

1. Monterrosa C A. actualización de conceptos en anticonceptivos orales combinados. (citado 2003 agosto 19). Disponible en: $h t t o: / / w w w . e n c o l o m b i a . c o m / a n t i c o n c e p t i v o s-$ introduccion.htm

2. Jiménez A M, Nogales O F. Citopatología ginecológica. Barcelona. Científico-Médica: 1977 p.39.

3. Y J S, Etienne Gloor. Comprehensive cáncer citopathology of the cervix uteri correlation with histopathology. New York. Mac Graw-Hill, 1995 v.4 p.156.

4. Atkinson B, S J. Atlas de dificultades diagnosticas en citopatología. Madrid España. Harcourt, 2000. p.31.

5. Geneser F. Histología sobre bases biomoleculares. 3 ed. Copenhagen: 2000; p. 633.

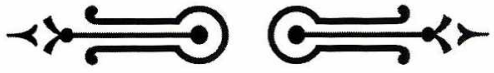

